\title{
Non-linear trade off between risk and return: A regime-switching multi-factor framework
}

\author{
Vicent Aragó ${ }^{\mathrm{a}}$ and Enrique Salvador ${ }^{\mathrm{a},{ }^{*}, 1}$ \\ ${ }^{\mathrm{a}}$ Finance and Accounting Department, Universitat Jaime I \\ Avenida Sos Baynat s/n, E-12071 Castellón de la Plana, Spain \\ * Corresponding author. Tel: +34 964 728577; Fax: +34 964 728565; E-mail: \\ esalvado@cofin.uji.es
}

\begin{abstract}
This paper examines the risk-return trade-off in Spain during the last 15 years. The study is developed in a multi-factor framework where not only the market risk is considered but also potential changes in the investment opportunity set. Although previous studies find no clear evidence about a positive and significant relation between return and risk, favourable evidence can be obtained if a non-linear relation between return and risk is established. Despite the importance of the intertemporal hedging component in the risk premium demanded by investors, the evidence obtained is independent of the choice of the proxy used. Different patterns for the risk premium dynamics in low and high volatility periods are obtained, both in risk prices and risk (conditional second moments) patterns.
\end{abstract}

Keywords: Non-linear model, Regime-Switching BEKK, ICAPM, multivariate GARCH, multi-factor models, investment opportunity set.

JEL code: G12, G15

\footnotetext{
${ }^{1}$ This author is grateful to Universitat Jaume I for support through the Research Personnel Training program (PREDOC/2007/12).

${ }^{a}$ The authors are grateful for financial assistance from Fundació Caixa Castelló-Bancaixa (P11B200616). The authors also appreciate the valuable comments and suggestions from the attendees of the seminars at Universidad Publica de Navarra and Universitat de les Illes Balears and the participants in the INFINITI (Dublin,2010), EWGFM (Istambul, 2010) and ASEPELT (Alicante, 2010) conferences.
} 


\section{Introduction}

The relation between expected return and risk has motivated many studies in the financial literature. Most of the recent asset pricing models are based in this fundamental trade-off, so understanding the dynamics of this relation is a key issue in finance. One of the first studies establishing a theoretical relation between expected return and risk is the Sharpe (1964) and Lietner (1965) CAPM model. These authors proposed a positive linear relationship between the expected return of any asset and its covariance with the market portfolio; in other words, the expected return of the market portfolio is proportional to its conditional variance. This static model has been analyzed empirically in several studies obtaining no clear evidence about the sign and significance of this relationship (Campbell 1987), Harvey 1989, Glosten et. al 1993). Merton (1973) proposed an extension of this model adding a second risk factor in the relationship that may improve the static CAPM model. The market risk premium in the Merton's model is proportional to its conditional variance and the conditional covariance with the investment opportunity set (hedging component). This framework established in a time-continuous economy is an extension of the static CAPM model assuming a stochastic set of investment opportunities. The expected market risk premium in equilibrium is:

$$
E_{t}\left(R_{M, t+1}\right)=\left[\frac{-J_{W W} W}{J_{W}}\right] \sigma_{m}^{2}+\left[\frac{-J_{W B} W}{J_{W}}\right] \sigma_{m b}
$$

where $J(\cdot)$ is the utility function (subindex represents partial derivatives), $E_{t}\left(R_{M, t+1}\right)$ is the expected excess market return, $\sigma_{m}^{2}$ and $\sigma_{m b}$ are, respectively, the conditional variance and the conditional covariance of the market excess return with the investment opportunity set, and $\left[\frac{J_{W B} W}{J_{W}}\right],\left[\frac{J_{W W} W}{J_{W}}\right]$ could be viewed as the risk prices of the sources of risk.

Assuming risk-averse investors $J_{W}>0$ and $J_{W W}<0$, the model establishes a positive relation between risk premium and market volatility. However, the relation between the risk premium with the second risk factor $\left(\sigma_{m b}\right)$ depends on the sign of $J_{W B}$ and $\sigma_{m b}$. If $J_{W B}$ and $\sigma_{m b}$ share the same sign the investors demand a lower risk premium, but if the sign is different a higher risk premium is demanded. Assuming that Equation 1 is the proper model for the empirical study of the risk-return trade-off, the omission of this risk factor could lead to misspecifications of the empirical models and misleading evidence about the risk-return relationship.

Despite the important role of this trade-off in the financial literature, there is no clear consensus about its empirical evidence. In the theoretical framework, all the parameters (the risk prices in brackets) and the variables (the sources of risk) are allowed to be 
time-varying. However, to make this model empirically tractable one must make several assumptions; the most common is considering constant risk prices (Goyal and SantaClara 2003, Bali et. al 2005). Another common assumption made in the empirical analysis of the risk-return trade-off is considering a set of investment opportunities constant over time, the market risk remaining as the only source of risk (Baille and Di Gennaro 1990, Glosten et al. 1993). This assumption leads to the validation of the static CAPM model. It is also necessary to assume specific dynamics for the conditional second moments. The most common are the GARCH models (Bollerslev 1986). ${ }^{2}$ Finally, the empirical model is established in a discrete time economy instead of the continuous time economy used in the equilibrium model of the theoretical approach. Many of the empirical papers studying the risk-return use one or more of the assumptions explained above.

The great controversy in the empirical validation of the risk-return trade-off is motivated by the disappointing results obtained about the sign and significance of this relation. There is no consensus about whether these results are due to: (1) wrong specifications of conditional second moments, Guo and Neely (2008), Leon et al. (2007); (2) misspecifications of the empirical models caused by the omission of the hedge component, Scruggs (1998); (3) both causes. However, another potential problem related with the empirical validation of the risk-return trade-off is the assumption of a linear relationship between return and risk. Some authors (Whitelaw 2000, Mayfield 2004) are concerned with this point and develop alternative theoretical models for the risk-return trade-off where non-linear patterns are included through regime-switching models. The equilibrium model in Whitelaw (2000) is slightly different from Merton's approach. A more complex, non-linear and time-varying relation between expected return and volatility is obtained. Whitelaw also remarks on the importance of the hedge component in the determination of the risk-return trade-off in his non-linear framework.

This study tries to shed light on the empirical validation of the risk-return trade-off. Although there is a large literature focused on the empirical validation of the ICAPM model, there are only few studies using multi-factor models that consider the hedge component $^{3}$. Furthermore, the main empirical approach used in the literature is the GARCH-M framework, which assumes a linear relation between return and risk. The weak evidence obtained in the existing literature could be due to a misspecification of the empirical model in terms of the dynamics for conditional second moments, by the omission of the hedge component, or by the assumption of a linear relationship between return and risk. Therefore, we incorporate all these features in our empirical models to analyze what are the key issues to consider in the empirical models that let us obtain favorable evidence as theoretical intuition suggests.

\footnotetext{
${ }^{2}$ Ghysels et al. (2005) proposes an alternative specification, the MIDAS regression, for modelling conditional second moments against GARCH models.

${ }^{3}$ One of the most common assumptions in the literature is the consideration of a constant set of investment opportunities, or, alternatively, independent and identically distributed rates of return. This assumption implies that the market risk premium only depends on its conditional variance and could be validated using univariate rather than multi-factor models.
} 
The main contributions of this paper are the following: Firstly, this study analyzes the risk premium evolution in Spain during the last few years. Secondly, it proposes a multi-factor model (considering a stochastic set of investment opportunities) where both the risk prices and sources of risk are state-dependent, allowing us to consider nonlinear relationships between them. Thirdly, it shows differences in the patterns followed by risk prices and conditional volatilities in different states. This non-linear framework allows us to distinguish between low and high volatility states.

Generally, the following results are noteworthy: a) The empirical results show that the risk price values are lower in high volatility states and the conditional volatility is more persistent in low volatility states. b) Favorable evidence for a positive and significant risk-return tradeoff in Spain is obtained, noting that the relevant aspect for this evidence is the assumption of a non-linear relation between return and risk, although the hedge component is also important in this framework.

This paper is organized as follows. Section 2 provides the data. Section 3 develops the empirical framework used in the paper. Section 4 gives the main empirical results and Section 5 concludes.

\section{Data description}

This study uses 720 weekly ${ }^{4}$ excess market returns from the Spanish market, including observations from 1 January 1996 to 15 October 2009. The excess market returns are computed using the quotations of the IBEX-35 index, first obtaining logarithmic returns ${ }^{5}$ and then subtracting from these returns the risk-free rate. Following Leon et al. (2007) the market money rate suitably compounded at the weekly frequency is used as the proxy for the risk-free rate. The choice for the proxy used as the hedging component against changes in the investment opportunity set are the followings rates for the Spanish market (Bali and Engle (2009, a,b) use these proxies for the American case): 1year Treasury bill, 3-year Treasury bond, 5-year Treasury bond, 10-year Treasury bond, an equally averaged portfolio with the previous 3 bonds and the difference between the yields on the 10-year and the 3-year Treasury bond. Thomson Datastream is used to obtain the data about the stock index, International Financial Statistics for the data corresponding to the risk-free rate and AFI for the data about the proxies used as the intertemporal hedging component. Table 1 shows the main summary statistics for excess market returns and the intertemporal hedging alternatives rates.

TABLE 1.- Summary statistics for excess market returns and intertemporal hedging proxies

\begin{tabular}{|l|c|c|c|c|c|c|c|}
\hline \multicolumn{7}{|c|}{ Panel A.- Summary statistics } \\
\hline & Excess & 1-year T- & 3-year T- & 5-year T- & 10-year T- & Averaged & Term \\
\hline
\end{tabular}

\footnotetext{
${ }^{4}$ Even though there are slight differences in the parameter estimations using different data frequency, there is no particular reason that the conclusions in this study should be affected by the selection of data frequency. Some authors remark on this point in their studies (De Santis and Imhoroglu 1997, Shin 2005, Lundblad 2007).

${ }^{5}$ We use logarithmic returns multiplied by 100 to facilitate the convergence of the empirical models.
} 


\begin{tabular}{|c|c|c|c|c|c|c|c|}
\hline & $\begin{array}{l}\text { market } \\
\text { return }\end{array}$ & bill & bond & bond & bond & portfolio & Spread \\
\hline Minimum & -23.032 & -0.7516 & -0.9480 & -1.319 & -3.220 & -1.893 & -1.298 \\
\hline Maximum & 13.784 & 0.6022 & 1.1246 & 1.854 & 2.363 & 1.662 & 1.698 \\
\hline Median & 0.1514 & 0.0116 & 0.0398 & 0.0606 & 0.0815 & -0.0335 & 0.0489 \\
\hline $\begin{array}{c}\text { Std. } \\
\text { deviation }\end{array}$ & 3.105 & 0.1039 & 0.2698 & 0.4447 & 0.6705 & 0.4706 & 0.4163 \\
\hline Skewness & -0.7825 & 0.4097 & -0.1785 & -0.1001 & -0.3863 & -0.3149 & -0.0790 \\
\hline Kurtosis & 8.808 & 13.386 & 4.1338 & 3.7837 & 4.271 & 3.781 & 3.775 \\
\hline $\mathrm{J}-\mathrm{B}$ & 1085.681 & 3256.582 & 42.392 & 19.631 & 66.450 & 30.198 & 18.798 \\
\hline L-B (6) & 42.186 & 61.842 & 30.622 & 21.217 & 18.997 & 15.924 & 20.596 \\
\hline L-B ${ }^{2}(6)$ & 224.899 & 251.798 & 132.371 & 151.362 & 68.0186 & 67.018 & 152.579 \\
\hline \multicolumn{8}{|c|}{ Panel B.- Correlation matrix } \\
\hline & $\begin{array}{c}\text { Excess } \\
\text { market } \\
\text { return }\end{array}$ & $\begin{array}{l}\text { 1-year T- } \\
\text { bill }\end{array}$ & $\begin{array}{l}\text { 3-year T- } \\
\text { bond }\end{array}$ & $\begin{array}{l}\text { 5-year T- } \\
\text { bond }\end{array}$ & $\begin{array}{l}\text { 10-year } \\
\text { T-bond }\end{array}$ & $\begin{array}{c}\text { Averaged } \\
\text { portfolio }\end{array}$ & $\begin{array}{c}\text { Term } \\
\text { Spread }\end{array}$ \\
\hline IBEX-35 & 1 & -0.0105 & -0.0830 & -0.0508 & -0.0317 & -0.0523 & -0.0516 \\
\hline $\begin{array}{r}1-\text { year } \\
\text { bill }\end{array}$ & . & 1 & 0.4319 & 0.3813 & 0.3059 & 0.3603 & 0.1576 \\
\hline $\begin{array}{c}\text { 3-year } \\
\text { bond }\end{array}$ & . & . & 1 & 0.9525 & 0.8420 & 0.9265 & 0.9096 \\
\hline $\begin{array}{c}5 \text {-year } \\
\text { bond }\end{array}$ & . & . & . & 1 & 0.9313 & 0.9815 & 0.9729 \\
\hline $\begin{array}{c}10 \text {-year } \\
\text { bond }\end{array}$ & . & . & . & . & 1 & 0.9773 & 0.9184 \\
\hline $\begin{array}{l}\text { Averaged } \\
\text { portfolio }\end{array}$ & . & . & . &. & . & 1 & 0.9585 \\
\hline $\begin{array}{c}\text { Term } \\
\text { Spread }\end{array}$ & . & . & . & . & . & . & 1 \\
\hline
\end{tabular}

Panel A shows summary statistics for excess markets returns and alternative hedging proxies. JB is the Jarque-Bera (1989) test for normality distribution. $L B(6)$ and $L B^{2}(6)$ are the Ljung-Box test for serial autocorrelation in levels and squares respectively. Panel B presents the correlation matrix for all the series included in this study.

All series included in this study present non-normal unconditional distributions with strong evidence for skewness and kurtosis. This result suggests fat tails in the unconditional distributions. Furthermore, all series exhibit conditional heteroskedasticity problems (serial autocorrelation in square returns). With these serial patterns, the use of GARCH models to represent the dynamics of conditional second moments, which has a large support in the previous literature, is totally understandable. It is also observed that the temporal series in levels do not exhibit serial autocorrelation so the inclusion of any structure ${ }^{6}$ in the mean equation is not necessary. Finally, the correlation matrix for the different proxies shows a low correlation between the excess returns of the market portfolio and the potential alternative investments. This result shows that the last series could be considered as proxies reflecting the alternative investment set available to the investors. Due to the lack of consensus in the literature

\footnotetext{
${ }^{6}$ The 1-year T-Bill series exhibit these problems, but after modelling the variance as a GARCH specification the serial autocorrelation disappears without including any lag in the mean equation.
} 
about the best proxy representing the alternative investment set (Scruggs and Glabadanidis 2003, Whitelaw 2006, Bali 2008), this study uses the different assets shown above which present different characteristics (in their terms and maturity) and add robustness to the study.

\section{Empirical methodology}

This section presents the empirical models used in the study. The main contribution of this paper is the assumption of a state-dependent risk price and state-dependent conditional volatilities, which implies a non-linear relationship between return and risk, following the equilibrium model in Whitelaw (2000). So, assuming bivariate GARCH dynamics for conditional volatilities, (more specifically, the BEKK model of Baba et. al (1990), state-independent multi-factor models that establish a linear relation between return and risk are presented in Section 3.1, followed by state-dependent multi-factor models that establish a non-linear risk-return trade-off through regime-switching both in the risk premium and conditional volatilities, in Section 3.2.

\subsection{State-independent multi-factor model}

This section presents a multi-factor model derived from Merton's (1973) ICAPM model. The 'general' model allows time-varying conditional second moments, but the risk aversion (risk price) coefficients for market risk $\left[\frac{J_{W B} W}{J_{W}}\right]$ and intertemporal component risk $\left[\frac{J_{W W} W}{J_{W}}\right]$ are constant over time (Scruggs and Glabadanidis 2003).

$$
\begin{aligned}
& r_{m, t}=\lambda_{10}+\lambda_{11} \sigma_{m, t}^{2}+\lambda_{12} \sigma_{m b, t}+\varepsilon_{m, t} \\
& r_{b, t}=\lambda_{20}+\lambda_{21} \sigma_{b m, t}+\lambda_{22} \sigma_{b, t}^{2}+\varepsilon_{b, t}
\end{aligned}
$$

where $\lambda_{i j}$ for $\mathrm{i}, \mathrm{j}=1,2$ are the parameters to estimate and represent the different risk prices and $\sigma_{m, t}^{2}, \sigma_{b, t}^{2}, \sigma_{m b, t}$ represent the conditional second moments (market variance, intertemporal hedging component variance and covariance between market portfolio and hedging component). A restricted model is also estimated, where the alternative investment set is time invariant $\left(\lambda_{21}=\lambda_{22}=0\right)$ (Scruggs 1998).

As we explained above, it is necessary make an assumption about the dynamics of the volatilities in order to empirically validate the theoretical ICAPM model. To analyze bivariate relationships, one of the most used models in the literature is the BEKK model of Baba et al. (1990). This model sets the following variance equation:

\footnotetext{
${ }^{7}$ The asymmetric response of volatility to news of different signs (leverage effect) is not considered for two reasons: (1) there is no improvement about the significance of the risk-return trade-off in previous studies (Aragó and Salvador 2010); (2) the convergence of the proposed models is harder to achieve due to the inclusion of the new parameters. These reasons lead to the consideration of a more parsimonious model.
} 


$$
H_{t}=\left(\begin{array}{cc}
\sigma_{m, t}^{2} & \sigma_{m b, t} \\
\sigma_{m b, t} & \sigma_{b, t}^{2}
\end{array}\right)=C C^{\prime}+A \varepsilon_{t-1} \varepsilon_{t-1}^{\prime} A^{\prime}+B H_{t-1} B^{\prime}
$$

where $C$ is a lower triangular $2 \times 2$ matrix of constants, $\mathrm{A}$ and $\mathrm{B}$ are $2 \times 2$ matrices of parameters, $\varepsilon_{t-1}$ is a Tx2 vector of innovations and $H_{t-1}$ is the lagged covariance matrix.

The model is estimated by the maximization of the QML function BollerslevWooldrige, assuming that the innovations follow a normal bivariate distribution $\varepsilon_{t} \sim N\left(0, H_{t}\right)$, which allows us to obtain robust estimates of standard errors.

$$
L(\theta)=\sum_{t=1}^{T} \ln \left[f\left(r_{t}, \Omega_{t} ; \theta\right)\right] \text { where } f\left(r_{t}, \Omega_{t} ; \theta\right)=(2 \pi)^{-1}\left|H_{t}\right|^{-\frac{1}{2}} \exp \left(-\frac{1}{2} \varepsilon_{t}^{T} H_{t}^{-1} \varepsilon_{t}\right)
$$

where $\left|\mathrm{H}_{\mathrm{t}}\right|$ represents the determinant of the covariance matrix and the remaining terms have been defined above.

\subsection{Regime-switching multi-factor model}

This section introduces a new multi-factor model where both the risk prices and the conditional second moments are dependent of the state in the economy. In this case, we propose two states ${ }^{8}$. The consideration of regime-switching in the empirical relation allows us to obtain state-dependent estimations for the risk prices and conditional second moments. This implies a non-linear and state-dependent relation between expected return and risk.

The mean equation specification in this model is

$$
\begin{aligned}
& r_{m, t, s_{t}}=\lambda_{10, s_{t}}+\lambda_{11, s_{t}} \sigma_{m, t, s_{t}}^{2}+\lambda_{12, s_{t}} \sigma_{m b, t, s_{t}}+\varepsilon_{m, t, s_{t}} \\
& r_{b, t, s_{t}}=\lambda_{20, s_{t}}+\lambda_{21, s_{t}} \sigma_{b m, t, s_{t}}+\lambda_{22, s_{t}} \sigma_{b, t, s_{t}}^{2}+\varepsilon_{b, t, s_{t}}
\end{aligned}
$$

for $s_{t}=1,2$ where $\lambda_{s_{t}}$ are state-dependent parameters, $r_{m, t, s_{t}}$ and $r_{b, t, s_{t}}$ are the statedependent excess market and hedging component returns, $\sigma_{m, t, s_{t}}^{2}, \sigma_{b, t, s_{t}}^{2}$ and $\sigma_{b m, t, s_{t}}$ are the state-dependent conditional second moments, and $\varepsilon_{m, t, s_{t}}$ and $\varepsilon_{b, t, s_{t}}$ are the statedependent innovations ${ }^{9}$.

\footnotetext{
${ }^{8}$ Previous studies considering three states (e.g., Sarno and Valente 2000) show that the third state only reflects odd jumps in the return series. The explanatory power of the third state is low and it is worthless in light of the difficulties of the estimation process that it produces.

${ }^{9}$ We also estimate a restricted model where $\lambda_{21}=\lambda_{22}=0$.
} 
It is assumed that the state-dependent conditional second moments follow a GARCH bivariate dynamics (more specifically, a BEKK model). That is, there are as many covariance matrices as states. The state-dependent covariance matrices are

$$
H_{t, s_{t}}=\left(\begin{array}{cc}
\sigma_{m, t, s_{t}}^{2} & \sigma_{m b, t, s_{t}} \\
\sigma_{m b, t, s_{t}} & \sigma_{b, t, s_{t}}^{2}
\end{array}\right)=C_{s_{t}} C_{s_{t}}{ }^{\prime}+A_{s_{t}} \varepsilon_{t-1} \varepsilon_{t-1}^{\prime} A_{s_{t}}{ }^{\prime}+B_{s_{t}} H_{t-1} B_{s_{t}}{ }^{\prime}
$$

The consideration of several states leads to a noteworthy rise in the number of parameters to estimate. In order to reduce this over-parameterization we only let parameters accompanying lagged innovations and lagged variances to be regimeswitching ${ }^{10}$. Furthermore, the difference among states is defined by two new parameters $s a$ and $s b$ that properly weight the estimations obtained in one state for the other state. Therefore, the state-dependent covariance matrices in our model are:

$$
\begin{aligned}
& H_{t, s_{t}=1}=\left(\begin{array}{cc}
\sigma_{m, t, 1}^{2} & \sigma_{m b, t, 1} \\
\sigma_{m b, t, 1} & \sigma_{b, t, 1}^{2}
\end{array}\right)=C C^{\prime}+A_{1} \varepsilon_{t-1} \varepsilon_{t-1}^{\prime} A_{1}^{\prime}+B_{1} H_{t-1} B_{1}^{\prime} \\
& H_{t, s_{t}=2}=\left(\begin{array}{cc}
\sigma_{m, t, 2}^{2} & \sigma_{m b, t, 2} \\
\sigma_{m b, t, 2} & \sigma_{b, t, 2}^{2}
\end{array}\right)=C C^{\prime}+A_{2} \varepsilon_{t-1} \varepsilon_{t-1}^{\prime} A_{2}^{\prime}+B_{2} H_{t-1} B_{2}^{\prime}
\end{aligned}
$$

where $A_{2}=s a \cdot A_{1}$ and $B_{2}=s a \cdot B_{1}, \mathrm{~A}_{1}$ and $\mathrm{B}_{1}$ are $2 \times 2$ matrices of parameters, and $\mathrm{C}$ is a $2 \times 2$ lower triangular matrix of constants (the same for the 2 states).

The shifts from one regime to another are governed by a hidden variable following a second order Markov process with transition matrix

$$
\hat{P}=\left(\begin{array}{cc}
\operatorname{Pr}\left(s_{t}=1 \mid s_{t-1}=1\right)=p & \operatorname{Pr}\left(s_{t}=1 \mid s_{t-1}=2\right)=(1-q) \\
\operatorname{Pr}\left(s_{t}=2 \mid s_{t-1}=1\right)=(1-p) & \operatorname{Pr}\left(s_{t}=2 \mid s_{t-1}=2\right)=q
\end{array}\right)
$$

where $\mathrm{p}$ and $\mathrm{q}$ are the probability of being in state 1 and 2 if in the previous period the process was in state 1 and 2 respectively.

Due to this state-dependence and the recursive nature of GARCH models, the construction and estimation of the maximum likelihood function would be intractable unless independent estimates for innovations and covariances were obtained. In order to solve this problem, we use a recombinative method similar to that used in Santos (1999) that lets us obtain state-independent estimations for the covariance matrix and the innovations weighting the state-dependent covariance matrix and innovations by the exante probability of being in each state.

$$
H_{t}=P\left(s_{t}=1 \mid \Omega_{t-1} ; \theta\right) H_{t, s_{t}=1}+P\left(s_{t}=2 \mid \Omega_{t-1} ; \theta\right) H_{t, s_{t}=2}
$$

\footnotetext{
${ }^{10}$ Capiello and Fearnley (2000) make a similar assumption to avoid potential convergence problems.
} 
$\varepsilon_{t}=P\left(s_{t}=1 \mid \Omega_{t} ; \theta\right) \varepsilon_{t, s_{t}=1}+P\left(s_{t}=2 \mid \Omega_{t} ; \theta\right) \varepsilon_{t, s_{t}=2}$

where $\mathrm{H}_{\mathrm{t}}$ and $\varepsilon_{\mathrm{t}}$ are the state-independent estimations for the covariance matrix and the innovations

The ex-ante probabilities (the probabilities of being in each state in the period $t$ using the information set at $\mathrm{t}-1)$ are (10.1) and (10.2):

$$
\begin{aligned}
& P\left(s_{t}=1 \mid \Omega_{t-1} ; \theta\right)=p^{*} P\left(s_{t-1}=1 \mid \Omega_{t-1} ; \theta\right)+(1-q) P\left(s_{t-1}=2 \mid \Omega_{t-1} ; \theta\right) \\
& P\left(s_{t}=2 \mid \Omega_{t-1} ; \theta\right)=1-P\left(s_{t}=1 \mid \Omega_{t-1} ; \theta\right)
\end{aligned}
$$

where

$$
P\left(s_{t}=k \mid \Omega_{t} ; \theta\right)=\frac{P\left(s_{t}=k \mid \Omega_{t-1} ; \theta\right) f\left(r_{t} \mid s_{t}=k, \Omega_{t} ; \theta\right)}{\sum_{k=1}^{2} P\left(s_{t}=k \mid \Omega_{t-1} ; \theta\right) f\left(r_{t} \mid s_{t}=k, \Omega_{t} ; \theta\right)}
$$

for $\mathrm{k}=1,2$ are the filtered probabilities (the probabilities of being in each state in the period $t$ with the information set up to $t$ ).

Assuming state-dependent innovations following a normal bivariate distribution $\varepsilon_{t, s_{t}} \sim N\left(0, H_{t, s_{t}}\right)$, the vector of unknown parameters $\theta$ is estimated by maximizing the following maximum-likelihood function:

$L(\theta)=\sum_{t=1}^{T} \ln \left[\sum_{k=1}^{2} P\left(s_{t}=k \mid \Omega_{t} ; \theta\right) f\left(r_{t}, \Omega_{t} ; \theta\right)\right]$ where $f\left(r_{t}, \Omega_{t} ; \theta\right)=(2 \pi)^{-1}\left|H_{t}\right|^{-\frac{1}{2}} \exp \left(-\frac{1}{2} \varepsilon_{t}^{T} H_{t}^{-1} \varepsilon_{t}\right)$

where the state-dependent likelihood function is weighted by the ex-ante probability of being in each state.

\section{4.- Empirical results}

This section presents the empirical results for the models proposed. We estimate the models explained in the previous section for the different proxies used as the intertemporal hedging component; models using the 1-year T-bill, the 3-year T-bond, the 5-year T-bond, the 10-year T-bond, the equally-weighted bond portfolio and the term spread are named .a, .b, .c, .d, .e, .f for brevity. Section 4.1 shows the results for the linear models (without regime-switching) in the two cases mentioned: general and restricted version. Section 4.2 explains the results for the non-linear multi-factor models (general and restricted), including regime switching. Section 4.3 describes the risk premium evolution in Spain during the last years according to each model and analyzes the reason for the differences between them. Finally, Section 4.4 performs some specification tests over the estimation residuals in order to detect any problems related with a potential misspecification of the empirical model. 


\section{1.- Multi-factor models estimations}

The estimated models in this section are those introduced in section 3.1. The case without restrictions is named general model and the restricted version are the model where we assume constant risk premiums for the hedge component $\lambda_{21}=\lambda_{22}=0$. The estimated parameters for the mean equation are presented in Table 2.

Table 2. Mean equation estimations for multi-factor models

\begin{tabular}{|c|c|c|c|c|c|c|c|}
\hline & \multicolumn{6}{|c|}{$\begin{array}{l}r_{m, t}=\lambda_{10}+\lambda_{11} \sigma_{m, t}^{2}+\lambda_{12} \sigma_{m b, t}+\varepsilon_{m, t} \\
r_{b, t}=\lambda_{20}+\lambda_{21} \sigma_{b m, t}+\lambda_{22} \sigma_{b, t}^{2}+\varepsilon_{b, t}\end{array}$} \\
\hline & & Model 2.a & Model 2.b & Model 2.c & Model 2.d & Model 2.e & Model 2.f \\
\hline \multirow{2}{*}{$\lambda_{10}$} & $\mathrm{R}$ & 0.1639 & 0.1192 & 0.1388 & 0.1851 & 0.1487 & 0.1297 \\
\hline & $G$ & 0.1722 & 0.1858 & 0.1706 & 0.1992 & 0.1782 & 0.1626 \\
\hline \multirow{2}{*}{$\lambda_{11}$} & $\mathrm{R}$ & 0.0125 & 0.0221 & 0.0151 & 0.0126 & 0.0190 & 0.0221 \\
\hline & $\mathrm{G}$ & 0.0107 & 0.0162 & 0.0163 & 0.0139 & 0.0176 & 0.0205 \\
\hline \multirow{2}{*}{$\lambda_{12}$} & $\mathrm{R}$ & -0.2247 & 0.4998 & 0.2283 & -0.0171 & 0.2779 & 0.4398 \\
\hline & $\mathrm{G}$ & -0.0433 & 0.7222 & 0.3634 & 0.0127 & 0.4165 & 0.5212 \\
\hline \multirow{2}{*}{$\lambda_{20}$} & $\mathrm{R}$ & 0.0008 & $0.0243^{* *}$ & $0.0387^{* *}$ & $0.0631^{* *}$ & $-0.0505 * * *$ & $0.0173^{* *}$ \\
\hline & $\mathrm{G}$ & -0.0033 & -0.0103 & -0.0187 & -0.0040 & $-0.1169 *$ & -0.0091 \\
\hline \multicolumn{2}{|c|}{$\lambda_{21} \mathrm{G}$} & 0.2417 & 0.0701 & 0.0864 & 0.0402 & 0.0688 & 0.0495 \\
\hline$\lambda_{22}$ & G & 0.2597 & 0.6618 & $0.4032^{*}$ & 0.1720 & 0.3700 & 0.6155 \\
\hline
\end{tabular}

Estimated parameters for the mean equation in multifactor models. ***, **and * represents significance at $1 \%, 5 \%$ and $10 \%$ levels.

It is clear that most of the parameters in this multi-factor model are non-significant for the mean equation. The coefficients that reflect the market risk price $\left(\lambda_{11}\right)$ are positive but non-significant in all cases considered. Similar results are obtained for the hedging component risk factor $\left(\lambda_{12}\right)$.

Table 3 shows the parameter estimates for the variance equation. These parameters define the dynamics and patterns followed by the conditional second moments.

Table 3. Variance equation estimations for multi-factor models

\begin{tabular}{|c|c|c|c|c|c|c|c|}
\hline & \multicolumn{6}{|c|}{$H_{t}=\left(\begin{array}{cc}\sigma_{m, t}^{2} & \sigma_{m b, t} \\
\sigma_{m b t} & \sigma_{b}^{2}\end{array}\right)=C C^{\prime}+A \varepsilon_{t-1} \varepsilon_{t-1}^{\prime} A^{\prime}+B H_{t-1} B^{\prime}$} \\
\hline & & Model 2.a & Model 2.b & Model 2.c & Model 2.d & Model 2.e & Model 2.f \\
\hline \multirow[b]{2}{*}{$c_{11}$} & $\mathrm{R}$ & $0.3068 * * *$ & $0.3403^{* *}$ & $0.3180^{* * * *}$ & $0.2912 * * *$ & $0.2971 * *$ & $0.3298^{* *}$ \\
\hline & $\mathrm{G}$ & $0.3017 * * *$ & $0.3276^{* *}$ & $0.3139 * * *$ & $0.2886^{* *}$ & $0.2972 * *$ & $0.3276^{*}$ \\
\hline \multirow{2}{*}{$c_{12}$} & $\mathrm{R}$ & $-0.0178 * *$ & -0.0256 & -0.0350 & -0.0427 & -0.0622 & -0.0183 \\
\hline & $\mathrm{G}$ & -0.0172 & -0.0178 & $-0.0283^{*}$ & -0.0407 & $-0.0475^{* *}$ & -0.0168 \\
\hline \multirow{2}{*}{$c_{22}$} & $\mathrm{R}$ & $0.0241 * * *$ & -0.0102 & $-2.80 \mathrm{E}-05$ & $0.1192 * * *$ & $9.00 \mathrm{E}-06$ & 0.01669 \\
\hline & $\mathrm{G}$ & $0.0242 * *$ & $8.76 \mathrm{E}-04$ & $-2.50 \mathrm{E}-07$ & $0.1162 * * *$ & $1.60 \mathrm{E}-08$ & -0.0102 \\
\hline \multirow{2}{*}{$a_{11}$} & $\mathrm{R}$ & $0.2815^{* * * *}$ & $0.2932 * * *$ & $0.2912 * * *$ & $0.2801 * * *$ & $0.3005^{* * *}$ & $0.2933 * * *$ \\
\hline & $\mathrm{G}$ & $0.2777 * * *$ & $0.2890 * * *$ & $0.2903 * * *$ & $0.2804 * * *$ & $0.2965^{* * *}$ & $0.2948 * * *$ \\
\hline \multirow{2}{*}{$a_{12}$} & $\mathrm{R}$ & -0.0024 & 0.0052 & 0.0092 & -0.0166 & 0.0034 & 0.0043 \\
\hline & $\mathrm{G}$ & -0.0019 & $0.0072^{*}$ & $0.0111^{* *}$ & -0.0141 & 0.0078 & 0.0052 \\
\hline
\end{tabular}




\begin{tabular}{|c|c|c|c|c|c|c|c|}
\hline \multirow{2}{*}{$a_{21}$} & $\mathrm{R}$ & $-1.4984 *$ & -0.7233 & -0.4042 & 0.0651 & -0.3442 & -0.6339 \\
\cline { 2 - 8 } & $\mathrm{G}$ & -1.5390 & -0.4929 & -0.3152 & 0.0618 & -0.2850 & -0.4930 \\
\hline \multirow{2}{*}{$a_{22}$} & $\mathrm{R}$ & $0.5630 * * *$ & $0.2190 * * *$ & $0.1846 * * *$ & $0.2421 * * *$ & $0.1807 * * *$ & $0.2264 * * *$ \\
\cline { 2 - 8 } & $\mathrm{G}$ & $0.5659 * * *$ & $0.1968 * * *$ & $0.1733 * * *$ & $0.2397 * * *$ & $0.1603 * * *$ & $0.2146 * * *$ \\
\hline \multirow{2}{*}{$b_{11}$} & $\mathrm{R}$ & $0.9556^{* * *}$ & $0.9509 * * *$ & $0.9527 * * *$ & $0.9586 * * *$ & $0.9514 * * *$ & $0.9526 * * *$ \\
\cline { 2 - 8 } & $\mathrm{G}$ & $0.9566^{* * *}$ & $0.9537 * * *$ & $0.9538^{* * *}$ & $0.9587 * * *$ & $0.9530 * * *$ & $0.9529 * * *$ \\
\hline \multirow{2}{*}{$b_{12}$} & $\mathrm{R}$ & $0.0012 *$ & -0.0022 & $-0.0040 * *$ & 0.0047 & -0.0019 & $-0.0020 *$ \\
\cline { 2 - 8 } & $\mathrm{G}$ & 0.0010 & -0.0026 & $-0.0044 * * *$ & 0.0038 & -0.0033 & -0.0022 \\
\hline \multirow{2}{*}{$b_{21}$} & $\mathrm{R}$ & $0.8897 * *$ & 0.3620 & 0.1950 & 0.0038 & 0.1849 & 0.3643 \\
\cline { 2 - 8 } & $\mathrm{G}$ & 0.8853 & $0.2680 * *$ & 0.1627 & 0.0084 & 0.1566 & 0.3219 \\
\hline \multirow{2}{*}{$b_{22}$} & $\mathrm{R}$ & $0.8118 * * *$ & $0.9675 * * *$ & $0.9761 * * *$ & $0.9491 * * *$ & $0.9734 * * *$ & $0.9664 * * *$ \\
\cline { 2 - 8 } & $\mathrm{G}$ & $0.8121 * * *$ & $0.9740 * * *$ & $0.9786 * * *$ & $0.9515 * * *$ & $0.9795 * * *$ & $0.9706 * * *$ \\
\hline
\end{tabular}

Estimated parameters for the variance equation in the multi-factor models. ***, ** and * represents significance at $1 \%, 5 \%$ and $10 \%$ levels.

The results reflect that the bivariate GARCH specification fit and properly capture the conditional second moments dynamics. Significance in the parameters representing shocks in volatility $\left(a_{11}, a_{22}\right)$ and persistence of past variance $\left(b_{11}, b_{22}\right)$ is observed for both risk factors (market risk and investment opportunity set component). However, the impact of one risk factor in the composition of the other factor's volatility is not significant, neither the impact of shocks $\left(a_{12}, a_{21}\right)$ nor persistence $\left(b_{12}, b_{21}\right)$. There is another remarkable result about volatility dynamics; the persistence level in the two sources of risk-market risk $\left(b_{11}\right)$ and hedging component $\left(b_{22}\right)$ - are relatively high using multi-factor models, with values close to 1 . This high persistence level suggests the presence of several regimes in the volatility process (Lameroux and Lastrapes 1990). Ignoring these regime shifts could lead to inefficient volatility estimations. Regime-Switching (RS)-GARCH models let us consider different states in the volatility, process as we explain in the next sub-section, and overcome this limitation.

\section{2- Regime-Switching multi-factor models estimation}

This section shows the estimations for the state-dependent models presented in Section 3.2. These models exhibit state-dependent risk prices and conditional moments. Table 4 describes the estimation for the state-dependent mean equation in all cases considered. As we explain below in Figure 2, we can associate states 1 and 2 with low and high volatility periods respectively.

Table 4.- Mean equation estimations for non-linear multi-factor models

\begin{tabular}{|c|c|c|c|c|c|c|c|}
\hline & \multicolumn{6}{|c|}{$\begin{array}{l}r_{m, t, s_{t}}=\lambda_{10, s_{t}}+\lambda_{11, s_{t}} \sigma_{m, t, s_{t}}^{2}+\lambda_{12, s_{t}} \sigma_{m b, t, s_{t}}+\varepsilon_{m, t, s_{t}} \\
r_{b, t, s_{t}}=\lambda_{20, s_{t}}+\lambda_{21, s_{t}} \sigma_{b m, t, s_{t}}+\lambda_{22, s_{t}} \sigma_{b, t, s_{t}}^{2}+\varepsilon_{b, t, s_{t}}\end{array}$} \\
\hline & & \multicolumn{6}{|c|}{ Panel A. Low volatility state $\left(\mathrm{s}_{\mathrm{t}}=1\right)$} \\
\hline & & Model 2.a & Model 2.b & Model 2.c & Model 2.d & Model 2.e & Model 2.f \\
\hline \multirow[t]{2}{*}{$\lambda_{10, s_{t}=1}$} & $\mathrm{R}$ & $-1.1540 * *$ & -0.8954 & $-2.3156^{* * *}$ & $-2.3689 * * *$ & $-2.7943 * * *$ & $-2.4819 * *$ \\
\hline & G & -0.8077 & $-1.5745^{* * *}$ & $-2.6614 * * *$ & $-2.5942 * * *$ & $-2.2375^{* * *}$ & $-4.0322 * * *$ \\
\hline \multirow{2}{*}{$\lambda_{11, s_{t}=1}$} & $\mathrm{R}$ & $0.4044 * *$ & $0.1169 * *$ & $0.1311 * *$ & $0.1867 * * *$ & $0.2980 * *$ & $0.2270 * *$ \\
\hline & G & $0.3415^{* *}$ & $0.1682 * *$ & $0.1144 * * *$ & $0.1982 * * *$ & $0.0758 * *$ & $0.3011 * *$ \\
\hline$\lambda_{1}$ & $\mathrm{R}$ & 2.7521 & 4.6265 & $3.7124 * *$ & $2.0452 * * *$ & $1.6691 * *$ & $1.3646 * * *$ \\
\hline
\end{tabular}




\begin{tabular}{|c|c|c|c|c|c|c|c|}
\hline & $\mathrm{G}$ & $7.6601 * * *$ & $1.8731 * *$ & -0.3294 & $2.5449 * * *$ & $0.0169 * *$ & $1.6573 * * *$ \\
\hline \multirow{2}{*}{$\lambda_{20, s_{t}=1}$} & $\mathrm{R}$ & 0.0099 & $0.0406 * *$ & $0.0742 * *$ & 0.0785 & $-0.0745 * *$ & $0.0524 * *$ \\
\hline & $\mathrm{G}$ & -0.0009 & 0.0096 & 0.4503 & -0.0172 & $-0.2907 * *$ & $0.1715 * * *$ \\
\hline \multicolumn{2}{|c|}{$\lambda_{21, s_{t}=1} \quad \mathrm{G}$} & -0.1518 & $0.1997 * * *$ & $0.4438 * *$ & -0.0479 & $-0.8829 * * *$ & $-0.4219 * *$ \\
\hline \multicolumn{2}{|c|}{$\lambda_{22, s_{t}=1} \quad \mathrm{G}$} & 1.8914 & 0.4396 & 0.9609 & 0.3025 & 0.2076 & $-1.3879 * *$ \\
\hline \multicolumn{8}{|c|}{ Panel B. High volatility state $\left(\mathrm{s}_{\mathrm{t}}=2\right)$} \\
\hline \multirow{2}{*}{$\lambda_{10, s_{t}=2}$} & $\mathrm{R}$ & $-1.4062 * *$ & $0.3597 * * *$ & $0.3436^{*}$ & $0.3502 * *$ & $0.2323 * * *$ & $0.2662 *$ \\
\hline & $\mathrm{G}$ & $-1.2897 * *$ & $0.1993 * *$ & 0.1891 & $0.3652 * *$ & $0.3583 * * *$ & $0.2908 * *$ \\
\hline \multirow{2}{*}{$\lambda_{11, s_{t}=2}$} & $\mathrm{R}$ & 0.0733 & 0.0198 & 0.0137 & 0.0043 & 0.0191 & 0.0153 \\
\hline & $\mathrm{G}$ & 0.0662 & $0.0302 * * *$ & 0.0337 & 0.0111 & 2.8310 & 0.0169 \\
\hline \multirow[t]{2}{*}{$\lambda_{12, s_{t}=2}$} & $\mathrm{R}$ & -1.2216 & 0.3280 & -0.3172 & -0.3739 & -0.0507 & -0.7152 \\
\hline & $\mathrm{G}$ & -1.4985 & 0.3132 & $0.7456^{*}$ & -0.4473 & -0.0323 & -0.2767 \\
\hline \multirow{2}{*}{$\lambda_{20, s_{t}=2}$} & $\mathrm{R}$ & -0.0027 & 0.0210 & 0.0354 & 0.0605 & $-0.0404 * *$ & $0.0183^{* *} *$ \\
\hline & G & $-0.0117 * * *$ & -0.0355 & $-0.1469 *$ & 0.03480 & -0.0768 & -0.0184 \\
\hline$\lambda_{21, s_{t}=2}$ & $\mathrm{G}$ & -0.1059 & $-0.1202 *$ & 0.1151 & 0.0637 & 0.0540 & -0.0215 \\
\hline$\lambda_{22, s_{t}=2}$ & $\mathrm{G}$ & 0.9297 & 1.0195 & $1.1358 * *$ & 0.0635 & 0.1869 & $0.7740 *$ \\
\hline
\end{tabular}

This table shows the estimated parameters for the mean equation in the non-linear multi-factor model. $* * *, * *$ and $*$ represents significance at $1 \%, 5 \%$ and $10 \%$ levels.

Positive and significant estimations for the market risk price in low volatility states $\left(\lambda_{11, \mathrm{~s}=1}\right)$ are obtained in all cases considered (for all proxies used as the intertemporal hedging component in the general and restricted version of the model $)^{11}$. A positive and significant influence over the market risk premium of the risk price is also observed, representing the covariance between risk premium and hedging component $\left(\lambda_{12, \mathrm{~s}=1}\right)$ in low volatility states. Generally, this covariance exhibits a negative influence in the total risk premium demanded (see Figure 1). So, the product of the risk price times the covariance between excess market return and hedging component $\left(\lambda_{12} \sigma_{m b, t, s_{t}=1}\right)$ shows that the total risk premium required by the investor $\left(\lambda_{11} \sigma_{m b, t, s_{t}=1}^{2}+\lambda_{12} \sigma_{m b, t, s_{t}=1}\right)$ is slightly lower than the market risk premium. Only when the covariance is positive does the premium associated with the hedging component lead to higher values of the total risk premium regarding the market risk premium.

Figure 1-Covariance between excess market returns and the intertemporal component

\footnotetext{
${ }^{11}$ The results for the intercept are also significant. Some authors (Ghysels et. al. 2005, Leon et al. 2007) interpret this fact as market imperfections.
} 


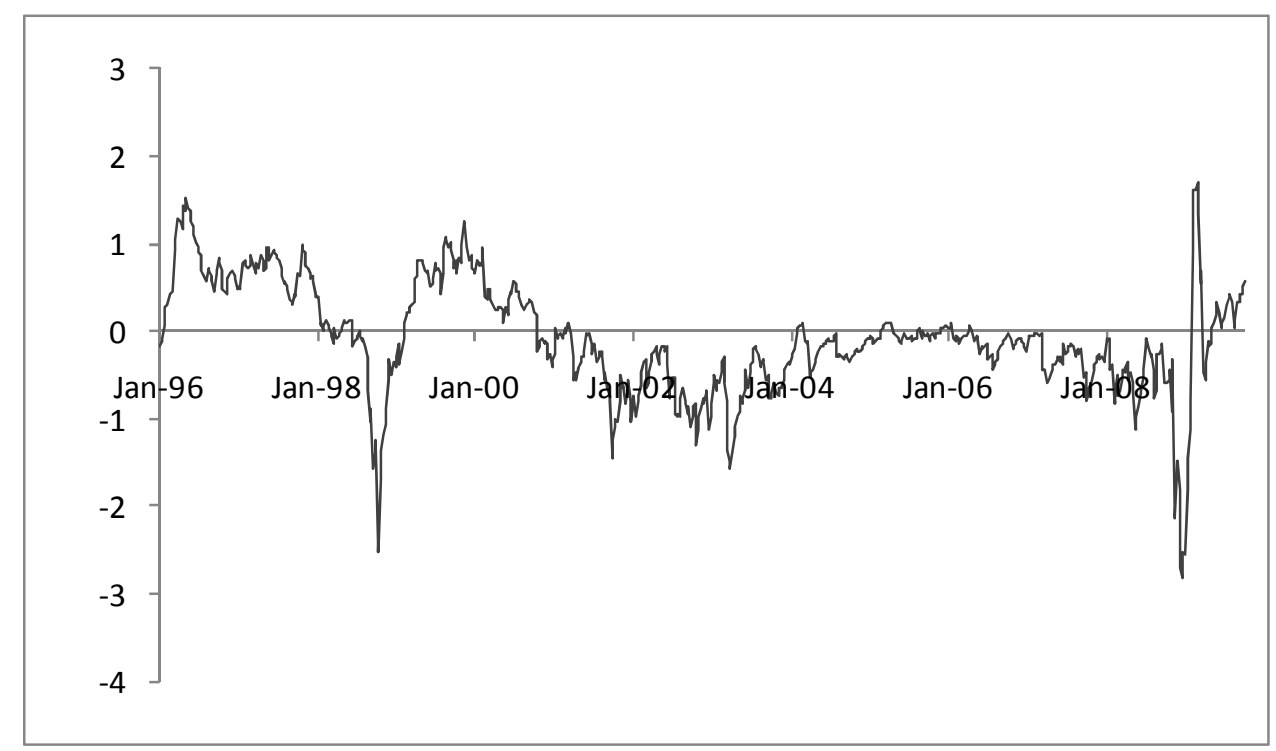

Covariance between excess market returns and 10-year T-bond used as intertemporal hedging component.

Panel B of Table 4 shows the results obtained for state 2. Generally, a significant relation is not observed between expected return and risk in high volatility states. A positive but no significant estimation is obtained for the risk price (market risk $\left(\lambda_{11, \mathrm{~s}=2}\right)$, and covariance between market risk and hedge component $\left(\lambda_{12, s=2}\right)$ ). Moreover, the risk aversion coefficients in state 1 (corresponding to low volatility states) are higher than those corresponding to state 2 (high volatility states). This result suggests that there is less risk aversion in high volatility states. This finding is not consistent with the spirit of the theoretical models that suggests that higher volatility should be compensated with higher returns. However, Mayfield (2004), Lettau and Ludvingson (2003), and Lundblad (2007) found the same evidence: during high volatility states there is a decreasing level of risk aversion. One possible explanation could be the different risk aversion profile for investors in each state (Schmeling, 2009). During calm (low volatility) periods more risk-averse investors are trading in markets, but in high volatility periods only the less risk-averse investors remain in the market because they are the only investors interested in assuming such risk levels, decreasing the risk premium demanded during these periods. However, the specification presented here may be confounding expected returns with realized returns, particularly in the less common high volatility states (corresponding generally with recession periods) often associated with low or even negative markets returns (Lundblad, 2007).

Table 5 shows the estimations for the state-dependent variance equations. Again, significant estimates are obtained for the parameters accompanying the shock impact $\left(a_{11}, a_{22}\right)$ and the persistence $\left(b_{11}, b_{22}\right)$ in the volatility formation in both risk factors. Most of the cross-relationships between factors $\left(a_{12}, a_{21}, b_{12}, b_{21}\right)$ in the volatility construction are non-significant, that is, shocks or volatility persistence in one factor has no effect in the other volatility factor. 
Table 5. Variance equation estimations for non-linear multi-factor models

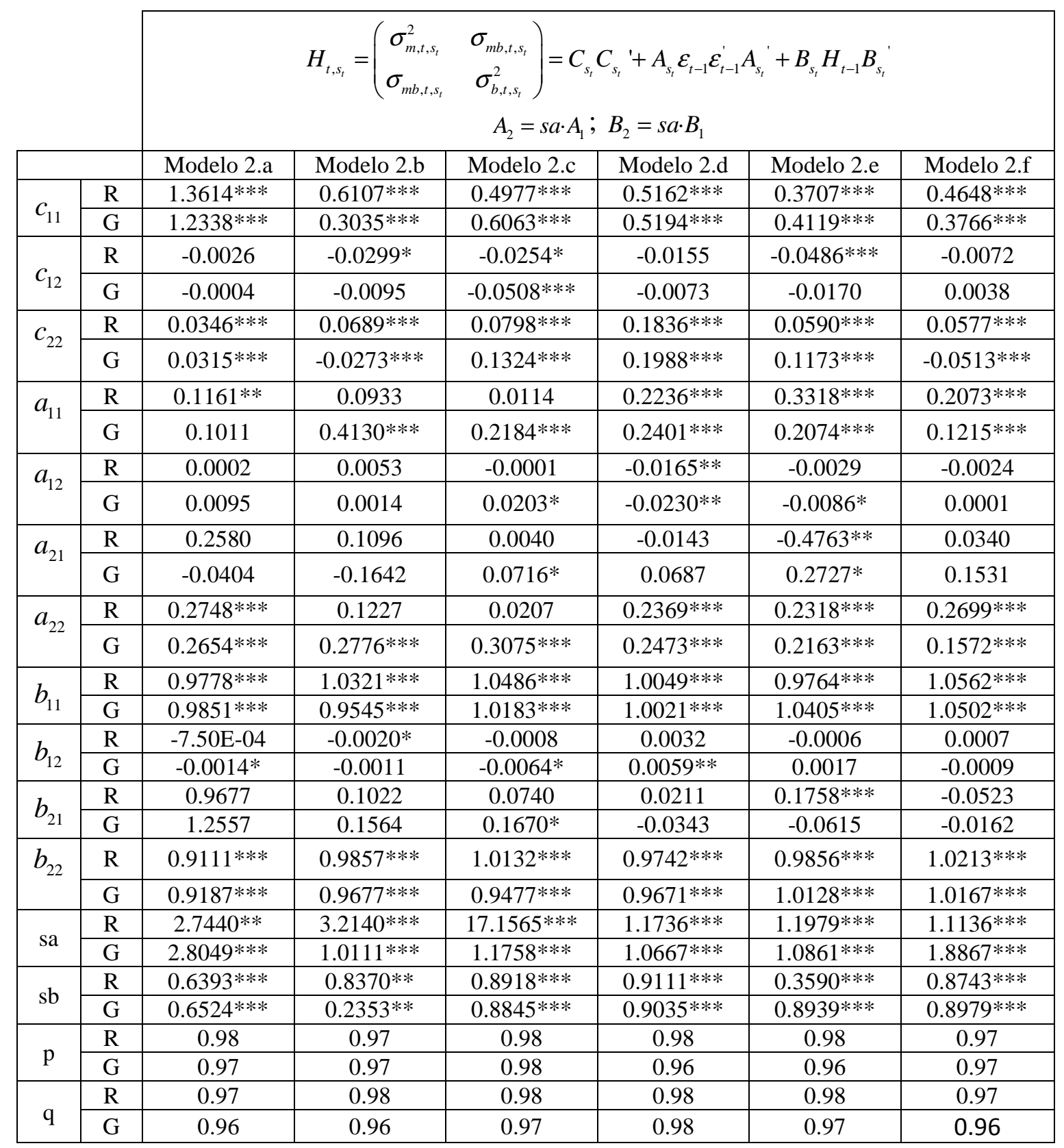

Estimated parameters for the variance equation in the non-linear multi-factor models. ***, ** and * represents significance at $1 \%, 5 \%$ and $10 \%$ levels.

Furthermore, the volatility formation depends on the regime considered in this framework. For low volatility regimes there is observed a higher influence of the lagged variance (matrix B) even than the non-switching case (with values higher than unity in some cases). Moreover, in these states, there is also a lower impact of shocks (matrix A) in volatility formation. This result means that the volatility observed in a period $t$ in a low volatility state is determined overall by the variance observed in the previous period and less by the shock occurring in period t. However, there is an increase of the shock influence in the volatility formation in high volatility regimes (determined by the product sa.A). There is also a decrease of the volatility persistence in these high volatility states $(\mathrm{sb} \cdot \mathrm{B})$. In this case, the volatility observed in a period $\mathrm{t}$ in a high volatility state is less determined by the variance observed in the previous period and 
more by the shock occurring in this period t. These results suggest that linear GARCH models could lead to sub-estimation of volatility persistence in high volatility periods and over-estimation of volatility persistence in high volatility periods, where there is a higher presence of shocks in volatility formation (Marcucci 2005).

In addition, the non-linear multi-factor model lets us associate the different states that follow the volatility process with low (state 1) and high volatility (state 2) market periods. The median of the estimated volatility for state 1 are $\hat{\sigma}_{M, s_{t}=1}^{2}=6.8718, \hat{\sigma}_{B, s_{t}=1}^{2}=$ 0.3740 and $\hat{\sigma}_{M B, s_{t}=1}=-0.0982$ while the median of estimated volatility series in state 2 are $\hat{\sigma}_{M, s_{t}=2}^{2}=8.5479, \hat{\sigma}_{B, s_{t}=2}^{2}=0.4496$ and $\hat{\sigma}_{M B, s_{t}=2}=-0.1215$. These results (jointly with Figure 2) let us associate the states defined in the non-linear model with low (state 1) and high volatility states (state 2 ).

Figure 1 show the smooth probabilities ${ }^{12}$ of being in state 1 during the sample period for the 10-year T-bond ${ }^{13}$ as hedging component case.

\section{Figure 2.- Smooth probabilities for low volatility states}

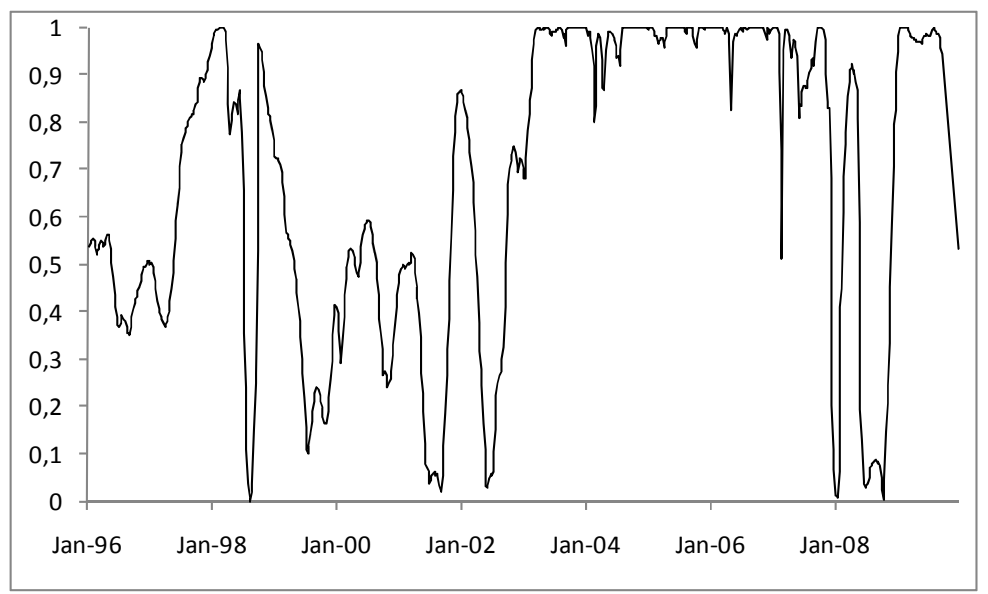

Probability of being in a low probability state for the case where the 10-yearT-bond is the alternative investment.

There are four patterns in the volatility process. The first part of the sample (until 2000 approximately) shows market uncertainty about the main regime in the market with sudden regime shifts (as the 1997 crisis). After that, high volatility periods seem to govern the process during the 2000-latest 2002 period, coinciding with the dot-com bubble. After this turbulent period, low volatility regimes govern again the Spanish market during the 2003-latest 2007 period, coinciding with a great expansion period of the Spanish economy. Then, coinciding with the global financial crisis of late 2007,

\footnotetext{
${ }^{12}$ The smooth probability is defined as the probability of being in each state considering the entire information set. $P\left(s_{t}=1 \mid \Omega_{T} ; \theta\right)=P\left(s_{t}=1 \mid \Omega_{t} ; \theta\right)\left[p \frac{P\left(s_{t+1}=1 \mid \Omega_{T} ; \theta\right)}{P\left(s_{t+1}=1 \mid \Omega_{t} ; \theta\right)}\right]+\left[(1-p) \frac{P\left(s_{t+1}=2 \mid \Omega_{T} ; \theta\right)}{P\left(s_{t+1}=2 \mid \Omega_{t} ; \theta\right)}\right]$

${ }^{13}$ For brevity, only the figure for the 10 -year $\mathrm{T}$-bond as alternative investment in the general model is considered; the dynamics of the probability in the rest of the cases are very similar. Results are available from the authors upon request.
} 
high volatility regimes govern again the volatility process. Despite these continuous changes in regime low volatility regimes show a higher presence during the sample period governing the volatility process. The number of periods where the volatility process is in a low volatility state (probability of being in a low volatility states is higher than 0.5 ) are 496 periods, corresponding to $69 \%$ of the total sample

The results obtained about the significance of the risk-return trade-off in both multifactor models suggest that the lack of empirical evidence in previous studies could be due to the strong assumption of a linear risk-return trade-off. Non-linear assumptions lead us to favorable evidence of the risk-return trade-off in low volatility states but we cannot obtain favorable evidence when a linear trade-off is assumed. We also obtain a significant impact of the intertemporal component in the risk-return relation similar to Whitelaw (2000).

Summing up, we can only obtain favorable evidence for a positive and significant riskreturn trade-off for low volatility regimes (state 1). As the differences in the risk price show, there is a real risk-return trade-off in this 'dominant' state, but such a relation is not observed in secondary states (high volatility). The lack of evidence in the linear case could be due to the existence of several periods in the sample where there is not a riskreturn trade-off (corresponding to secondary states), causing a non-significant riskreturn trade-off for the whole sample. However, if we distinguish among states we can identify dominant and secondary states and identify a significant trade-off essentially in the dominant state.

\section{3.- Risk premium evolution}

This section describes the risk premium evolution demanded by the investors in Spain, distinguishing between what proportions of the risk premium correspond to each risk factor: the market risk and the hedging component. We compute the premium associated with the market risk by the product of the risk price with idiosyncratic risk $\lambda_{11} \sigma_{m, t}^{2}$ for linear multi-factor models (and similarly for the hedging component premium). For the non-linear case, this risk premium is obtained using the statedependent market risk premium weighted by the smooth probability of being in each state $P\left(s_{t}=1 \mid \Omega_{T} ; \theta\right) \lambda_{11, s_{t}} \sigma_{m, t, s_{t}}^{2}+P\left(s_{t}=1 \mid \Omega_{T} ; \theta\right) \lambda_{11, s_{t}} \sigma_{m, t, s_{t}}^{2}$ (and similarly for the hedging component premium). The total risk premiums are computed by the sum of the two factor premiums.

For brevity, we only show the results corresponding to the 10-year T-bond as alternative investment case. ${ }^{14}$ Figure 2 describes the risk premium for the linear and non-linear cases.

\section{Figure 2.- Risk Premium evolution in Spain}

\section{Figure 2.a.- Risk Premium for the linear multi-factor model}

\footnotetext{
${ }^{14}$ The dynamics of the risk premium evolution in the rest of the cases are very similar. Results are available from the authors upon request.
} 


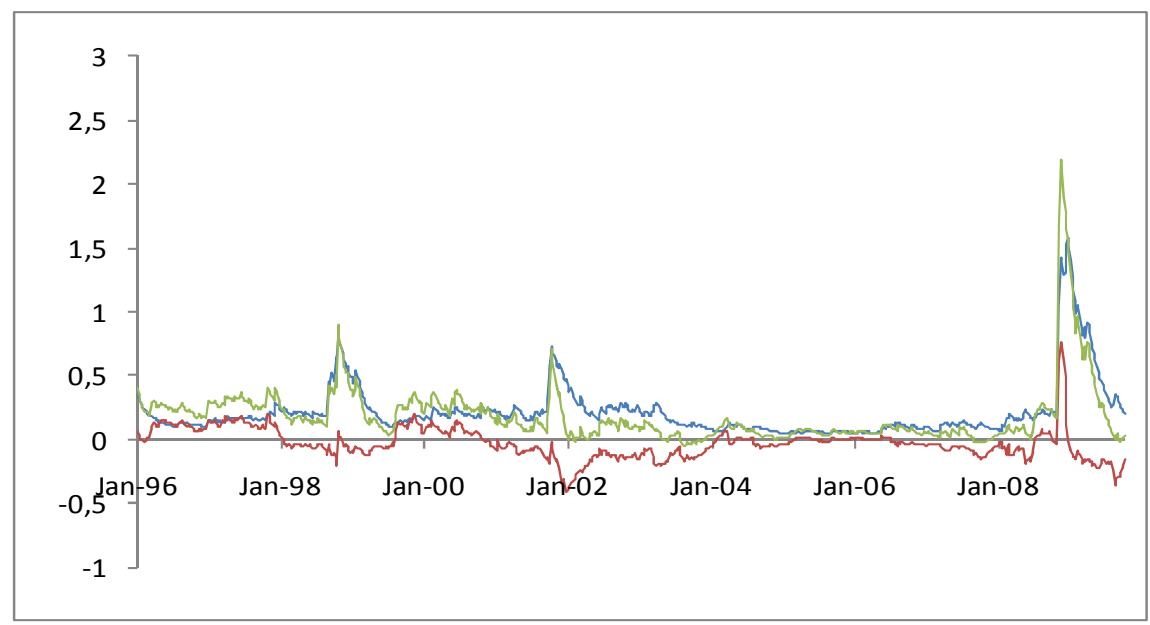

Estimated risk premium for the Spanish market using the linear multi-factor model. The greenline is the market risk, the red line is the premium associated with the hedging component and blue line represents the total risk premium.

Figure 2.b.- Risk Premium for the non- linear multi-factor model

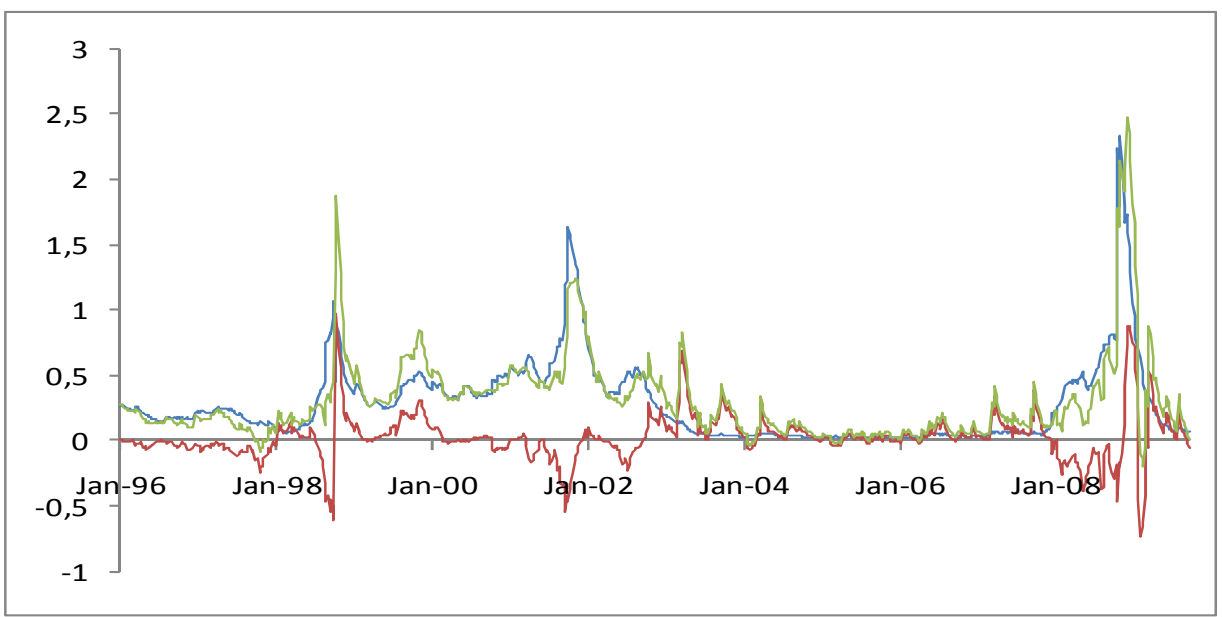

Estimated risk premium for the Spanish market using the non- linear multi-factor model. The greenline is the market risk, the red line is the premium associated with the hedging component and blue line represents the total risk premium.

Both figures share similar patterns and only differ because of the scale of the risk price. The dynamics for the source of risk are very similar. There is a common rise of the market risk premium coinciding with high volatility periods (dot-com bubble period (2000-2002) and the last financial crisis (2007-2009)). The median ${ }^{15}$ of the weekly risk premiums series shows that over the past 15 years the risk premium in Spain has remained at approximately $4 \%$ to $7 \%$ per annum ${ }^{16}$ depending on the model used. Furthermore, the total risk premium is essentially defined for the risk associated with the market. The percentage of the total risk premium corresponding to the hedging component is relatively small for the linear model. More specifically, over the total risk

\footnotetext{
${ }^{15}$ We use the median rather the mean of the conditional second moments as a proxy for the average nondiversifiable risk in each period because it is less affected by outliers.

${ }^{16}$ The descriptive statistics for the risk premiums are not shown but they are available from the authors upon request.
} 
premium estimated, only $95.5 \%$ and $74 \%$ of the premium are due to the market factor in the linear and non-linear multi-factor models respectively.

In order to detect the differences in the risk premium between the models proposed, Figure 3 presents the evolution of the differences between the total risk premium obtained in each model ${ }^{17}$.

\section{Figure 3.- Risk Premium differences between linear and non-linear models}

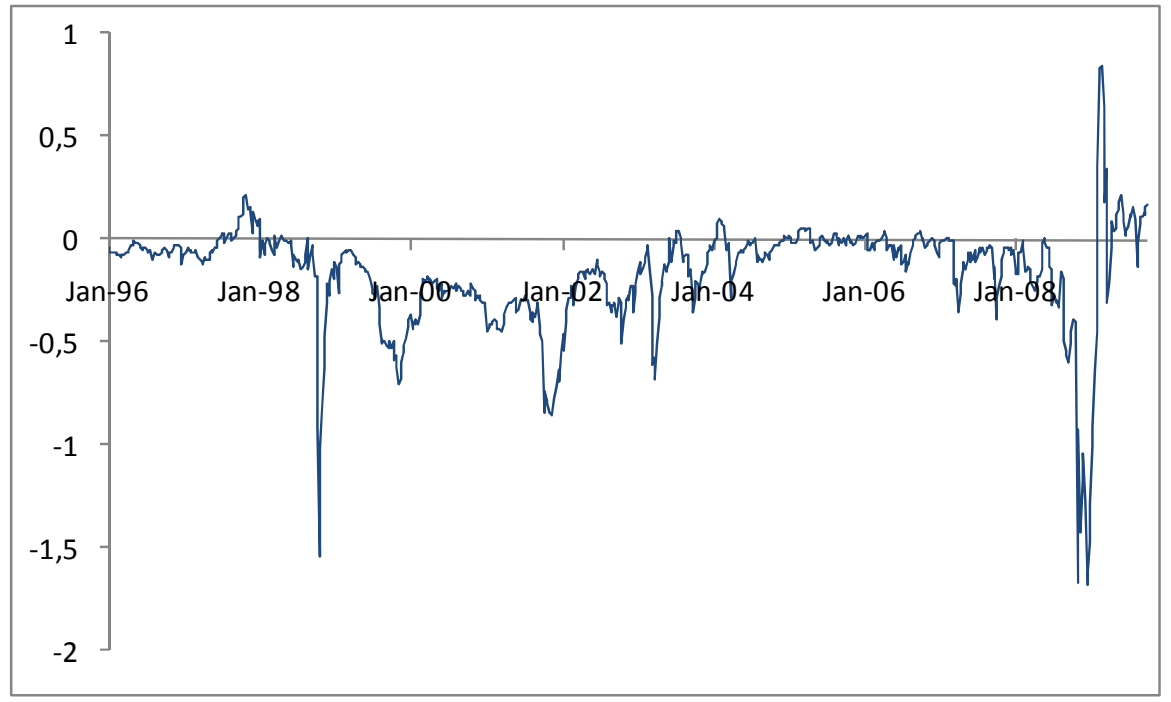

Differences in the total risk premium estimated using linear and non-linear multi-factor model.

A similar evolution of the total risk premium is observed in both models during low volatility states (2002-2007). However, non-linear models exhibit higher estimations of the risk premium during high volatility periods (such as 2000-2002 and 2008 periods). According to this evidence, the assumption of linear patterns in the risk-return trade-off could lead to underestimations of the risk premium in high volatility periods.

\section{4.- Specification test}

This section performs several specification tests in order to check the adequacy of the QML estimations of the multi-factor models. For this reason, we analyze the properties of the standardized residuals $\left(\epsilon_{i, t}=\varepsilon_{i, t} / \sqrt{h_{i i, t}}\right)$ and the product of the standardized residuals for the models proposed. Only the results for the 10 -year T-bond case ${ }^{18}$ are shown for brevity for the linear and non-linear models.

\section{Table 6.- Specification test for the standardized residuals}

\begin{tabular}{|c|c|c|c|c|c|}
\hline $\begin{array}{c}\text { Panel A.- Linear } \\
\text { Model }\end{array}$ & $\hat{\epsilon}_{m, t}$ & $\hat{\epsilon}_{b, t}$ & $\hat{\epsilon}_{m, t}^{2}$ & $\hat{\epsilon}_{m, t} \hat{\epsilon}_{b, t}$ & $\hat{\epsilon}_{b, t}^{2}$ \\
\hline Mean & -0.0643 & 0.0078 & 0.9850 & 0.0162 & 1.013 \\
\hline
\end{tabular}

\footnotetext{
${ }^{17}$ For brevity, only the figure for the 10-year T-bond as alternative investment in the general model are shown; the dynamics of the differences in the risk premium evolution in the rest of the cases are very similar. Results are available from the authors upon request.

${ }^{18}$ Results for all models are available from the authors upon request
} 


\begin{tabular}{|c|c|c|c|c|c|}
\hline Std. Dev & 0.9910 & 1.007 & 2.9696 & 1.377 & 1.760 \\
\hline Skewness & -1.072 & -0.4084 & 18.9559 & 7.897 & 5.684 \\
\hline Kurtosis & 9.857 & 4.0290 & 443.3336 & 138.792 & 61.417 \\
\hline J-B test & $1546.78^{* *}$ & $51.714^{* *}$ & $5851793.34^{* *}$ & $559890.43^{* *}$ & 106 \\
\hline L-B (6) & 24.507 & 16.609 & 6.927 & 20.2143 & $109.44^{* *}$ \\
\hline t-stat for H0: & -1.740 & 0.2096 & & & \\
\hline t-stat for H1: & & & -0.1354 & 0.3156 & 0.1993 \\
\hline $\begin{array}{c}\text { Panel B.- } \\
\text { Non linear- } \\
\text { Model }\end{array}$ & $\hat{\epsilon}_{m, t}$ & $\hat{\epsilon}_{b, t}$ & $\hat{\epsilon}_{m, t}^{2}$ & $\hat{\epsilon}_{m, t} \hat{\epsilon}_{b, t}$ & $\hat{\epsilon}_{b, t}^{2}$ \\
\hline Mean & 0.0271 & -0.0037 & 1.075 & 0.0374 & 0.9877 \\
\hline Std. Dev & 1.0375 & 0.9945 & 2.250 & 1.236 & 1.5652 \\
\hline Skewness & -0.4701 & -0.3271 & 10.508 & 2.550 & 3.5096 \\
\hline Kurtosis & 5.42261 & 3.50276 & 176.96414 & 32.28573 & 22.115248 \\
\hline J-B test & $202.31153^{* *}$ & $20.40111^{* *}$ & $919878.21^{* *}$ & $26473.38^{* *}$ & $12422.63 * *$ \\
\hline L-B (6) & 28.57888 & 17.44660 & 17.37963 & 10.78957 & 19.30694 \\
\hline t-stat for H0: & 0.70157 & -0.10188 & & & \\
\hline t-stat for H1: & & & 0.90324 & 0.81193 & -0.21049 \\
\hline
\end{tabular}

This table shows the statistics for the standardized residuals for both models used: GARCH-M and RSGARCH framework. J-B test is the Jarque-Bera test for normality. L-B (6) is the Ljung-Box autocorrelation test including 6 lags. It also presents tests about the first two moments of the standardized residuals to validate consistent estimations of the QML procedure from deviations to normality. .**, **, * represent significance at $1 \%, 5 \%$ and $10 \%$ levels. $\mathrm{H} 0$ and $\mathrm{H} 1$ represent the $\mathrm{t}$-statistic for the two moment order test developed in Bollerslev-Wooldrige (1992).

The first part of the table shows summary statistics for the standardized residuals of the estimated multi-factor models. The mean value is around 0 in both cases with a standard deviation nearly to 1 . The two cases (linear and non-linear) exhibit good properties. A reduction in the skewness and kurtosis of the residuals is observed compared to the original series. An even higher reduction is observed in the skewness and kurtosis in the non-linear case, suggesting a more accurate description and fit of the conditional second moment dynamics. The Ljung-Box test performed over the standardized residuals reveal a lack serial autocorrelation neither in levels nor in their cross-products. It is also removed the original heterokedasticty problem present in the original series.

The bottom of the table presents two moment tests to analyze the consistence of the QML estimations performed (Bollerlev and Wooldrige (1992)). These authors explain that, even in deviations from normality, consistent estimations are obtained if $E_{t-1}\left(\hat{\epsilon}_{i, t}\right)=0, E_{t-1}\left(\hat{\epsilon}_{i, t}^{2}\right)=1$ and $E_{t-1}\left(\hat{\epsilon}_{i, t} \hat{\epsilon}_{j, t}\right)=0$ for $\mathrm{i}, \mathrm{j}=\mathrm{m}, \mathrm{b}$ where $\hat{\epsilon}_{i, t}$ are the standardized residuals.

The results obtained do not reject the null hypothesis assumed about the considered value of the two first order moments. These results confirm the consistency of the estimations of our models even for deviations from normality.

\section{$\underline{\text { 5.- Conclusion }}$}

This paper analyzes empirically the risk-return trade-off for the Spanish market using several proxies for the alternative investment set. We propose two multi-factor models considering conditional second moments according a bivariate GARCH specification in 
a linear and non-linear framework (using a model with regime-switching GARCH). The results show that only a positive and significant risk-return trade-off is obtained in the non-linear case and only in the states governed by low volatility process (State 1). The evidence suggested in the theoretical intuition is only observed in the 'dominant' volatility states. The weight of the hedging component in the risk premium is less important than the market risk factor although the former has also a significant impact in low volatility periods. However, it is found no favorable evidence either in the linear framework or in secondary volatility states (high volatility). Strong assumptions of a linear relation between return and risk could lead to model misspecification and an inability of the empirical model to capture a significant risk-return relationship since the existence of periods where a risk-return trade-off is not observed could lead to nonsignificant estimation of this relation for the entire sample.

The risk premium evolution in Spain is close to the market volatility. The risk premium demanded for the investors presents a higher value than other sample periods during 2000-2003 and 2007-2009 (coinciding with crisis periods). It is also observed a lower risk price during high volatility periods than the observed in low volatility states. The investor profile in each context may also have influence in this lower risk aversion coefficient during high volatility periods although this approach may be confounding realized (often lower even negative during high volatility states) with expected returns. Despite the decrease in the risk price, there is an extremely rise in the market risk that lead to higher risk premiums during the high volatility periods. The two multi-factor models also estimate noteworthy different risk premium during these periods. Nonlinear models estimate higher risk premium during these periods, although for the rest of the sample the estimations are quite similar. Furthermore, the linear framework presents higher persistence of volatility shocks in the volatility formation during low volatility periods (and vice-versa). This fact is corrected with the introduction of the regime-switching, obtaining lower persistence volatility estimation in high volatility periods and higher persistence volatility estimation in low volatility periods.

In sum, the non-linear framework presented here shows an improvement about the empirical evidence of the risk-return trade-off in Spain not only about the significance of the relationship but also in the estimated risk premium in high volatility periods.

\section{$\underline{\text { References }}$}

Adler, M., and B. Dumas (1983): "International Portfolio Selection and Corporation Finance: a Synthesis," Journal of Finance, 46, 925-984

Aragó, V., and E. Salvador (2010): Re-examining the risk-return relationship: The influence of financial crisis (2007-2009). Working paper, Universitat Jaume I of Castellón.

Baba, Y., R. Engle, D. Kraft, and K. Kroner (1990): Multivariate simultaneous generalized ARCH, Unpublished Working Paper, mimeo, University of California at San Diego. 
Baillie, R., and R. De Gennaro (1990): “Stock returns and volatility," Journal of Financial and Quantitative Analysis, 25 (2), 203-214.

Bali, T., N. Cakici, X. Yan, and Z. Zhang (2005): "Does idiosyncratic risk really matter?" Journal of Finance, 60(2), 905-929.

Bali, T. (2008): "The intertemporal relation between expected returns and risk," Journal of Financial Economics, 87(1), 101-131.

Bali, T., and R. Engle (2009): Investigating the ICAPM with Dynamic Conditional Correlations. Working Paper, Baruch College, CUNY, and New York University.

Bali, T., and R. Engle (2009): A cross-sectional investigation of the conditional ICAPM. Working Paper, Baruch College, CUNY, and New York University.

Bollerslev, T. (1986): "Generalised autoregressive conditional heteroskedasticity," Journal of Econometrics, 31(3), 307-327.

Bollerslev, T., and J. Wooldridge (1992): "Quasi-maximum likelihood estimation and inference in dynamic models with time-varying covariances." Econometric Reviews, 11(2), 143-172.

Capiello, L., and T. Fearnley (2000): International CAPM with Regime-Switching Parameters. FAME Research Paper Series, rp17, International Center for Financial Asset Management and Engineering (Geneva, Switzerland).

Engle, R., D. Lilien, and R. Robins (1987): "Estimating Time Varying Risk Premia in the Term Structure: The ARCH-M Model." Econometrica, 55(2), 391-407.

French, K., G. Schwert, and R. Stambaugh (1987): "Expected stock returns and variance," Journal of Financial Economics, 19(1), 3-29.

Ghysels, E., P. Santa-Clara, and R. Valkanov (2005): "There is a risk-return trade-off after all." Journal of Financial Economics, 76(3), 509-548.

Ghysels, E., A. Sinko, and R. Valkanov (2007): "MIDAS Regressions: Further Results and New Directions," Econometric Reviews, 26(1), 53-90

Glosten, L., R. Jagannathan, and D. Runkle (1993): "On the relation between the expected value and the variance of the nominal excess return on stocks." Journal of Finance, 48(5), 1779-1801.

Goyal, A., and P. Santa-Clara (2003): "Idiosyncratic risk matters!" Journal of Finance, 58(3), 975-1008.

Gray, S. (1996): "Modelling the conditional distribution of interest rates as a regimeswitching process," Journal of Financial Economics, 42(1), 27-62.

Guo, H., and C. Neely (2008): "Investigating the intertemporal risk-return relation in the international stock markets with the component GARCH model," Economics letters, 99, 371-374.

Guo H., and R. Whitelaw (2006): "Uncovering the Risk-Return Relation in the Stock Market," Journal of Finance, 61(3), 1433-1463.

Hamilton, J. (1989): "A new approach to the economic analysis of nonstationarity time series and business cycle," Econometrica, 57(2), 357-384

Hamilton, J. (1994): Time Series Analysis, Princeton Univ. Press. 
Harvey, C. (1989): "Time-varying conditional covariances in tests of asset pricing models," Journal of Financial Economics, 24, 289-317.

Laporta, R., F. López de Silanes, and A. Shleifer (1999): "Corporate ownership around the world," Journal of Finance, 2(2), 471-517

León, A., J. Nave, and G. Rubio (2007): "The relationship between risk and expected return in Europe," Journal of Banking and Finance, 31, 495-512.

Lintner, J. (1965): "The Valuation of Risk Assets and Selection of Risky Investments in Stock Portfolios and Capital Budgets," Review of Economics and Statistics, 47, 1337.

Lundblad, C. (2007) "The risk-return trade-off in the long run: 1836-2003," Journal of Financial Economics, 85(1), 123-150.

Marcucci, J. (2005): "Forecasting Stock Market Volatility with Regime-Switching GARCH Models," Studies in Nonlinear Dynamics \& Econometrics, 9 nº 4, Article 6.

Merton, R. (1973): “An intertemporal asset pricing model,” Econometrica, 41(5), 867888.

Santos, A. (1999): Capital Asset Pricing Model and Changes in Volatility, FAME Research Paper Series, rp4, International Center for Financial Asset Management and Engineering.

Sarno, L., and G. Valente (2000): "The cost of carry model and regime shifts in stock index futures markets; An empirical investigation," The Journal of Futures Markets, 20, 603-624.

Schmeling, M. (2009): "Investor sentiments and stock returns: Some international evidence," Journal of Empirical Finance, 16, 394-408

Scruggs, J. (1998): "Resolving the puzzling intertemporal relation between the market risk premium and conditional market variance: A two-factor approach." Journal of Finance, 53(2), 575-603.

Scruggs, J., and P. Glabadanidis (2003): "Risk premia and the dynamic covariance between stock and bond returns," Journal of Financial and Quantitative Analysis, 38(2), 295-316.

Sharpe, W. (1964): "Capital Asset Prices: A Theory of Market Equilibrium Under Conditions of Risk," Journal of Finance, 19, 425-442. 